\title{
THE RESULTS OF TRABECULECTOMY USING A SUTURELESS SCLERAL TUNNEL TECHNIQUE
}

\author{
Motup Angmo1, Andleeb Ahangar', Mohamed Ahsan Dar', Manzoor Qadir Keng ${ }^{4}$, Ankur Goel ${ }^{5}$ \\ ${ }^{1}$ Resident, Department of Ophthalmology, Government Medical College, Srinagar, Kashmir, India. \\ ${ }^{2}$ Registrar, Department of Ophthalmology, Government Medical College, Srinagar, Kashmir, India. \\ ${ }^{3}$ Associate Professor, Department of Ophthalmology, Government Medical College, Srinagar, Kashmir, India. \\ 4 Professor, Department of Ophthalmology, Government Medical College, Srinagar, Kashmir, India. \\ ${ }^{5}$ Resident, Department of Ophthalmology, Government Medical College, Srinagar, Kashmir, India.
}

\section{ABSTRACT}

\section{BACKGROUND}

To study the success rate in terms of control of Intraocular Pressure (IOP) using sutureless scleral tunnel trabeculectomy and to study the complications of this technique.

\section{METHODS}

This prospective study was conducted on 50 eyes of the patients diagnosed with primary open angle glaucoma uncontrolled by medication. All patients underwent sutureless scleral tunnel trabeculectomy and were followed up for a period of six months. At each follow-up, detailed ocular examination was done including visual acuity, slit lamp examination, intraocular pressure measurement and fundus examination. Post-operative complications were also recorded.

\section{RESULTS}

In our study, the age of the patients ranged from 31-75 years with a mean age of $60.86 \pm 9.09$ years. Majority (76\%) of the patients were male. Pre-operative mean intraocular pressure was $30.56 \pm 7.16 \mathrm{mmHg}$. Post-operatively mean intraocular pressure was $16.00 \pm 2.32 \mathrm{mmHg}$ at 6 months. Average post-operative fall of intraocular pressure from initial level was $14.56 \mathrm{mmHg}$ at $6 \mathrm{months}$. The fall in intraocular pressure was statistically significant. Visual acuity was maintained at a pre-operative level in majority 43 $(86 \%)$ cases, at the end of follow-up period. Post-operative complications were seen in $14(28 \%)$ cases with the main complication being shallow anterior chamber. Other post-operative complications were hyphema, post-operative inflammation and cataract development. Absolute success rate was seen in $90 \%$ of the cases.

\section{CONCLUSION}

From this study it can be concluded that the sutureless scleral tunnel trabeculectomy is a safe, easy and effective modification of the conventional procedure, which can be used for treating uncontrolled primary open angle glaucoma.

\section{KEYWORDS}

Primary Open Angle Glaucoma, Sutureless, Trabeculectomy, Intraocular Pressure, Complications.

HOW TO CITE THIS ARTICLE: Angmo M, Ahangar A, Dar MA, et al. The results of trabeculectomy using a sutureless scleral tunnel technique. J. Evolution Med. Dent. Sci. 2016;5(39):2379-2382, DOI: 10.14260/jemds/2016/553

\section{INTRODUCTION}

Conventional trabeculectomy has many complications like intraoperative lacerations of scleral flap, intraoperative bleeding, excessive tissue damage, local irritation due to use of sutures.[1] hypotony, shallow anterior chamber and choroidal detachment. Aim of glaucoma surgery is to maintain a steady flow of aqueous out of the anterior chamber through the scleral window, under the scleral flap into the subconjunctival space. But maintaining the right amount of flow is a challenge to the surgeon. The bleb can be a failure due to overfiltration (Hypotony) or underfiltration (Hypertony). Very tight sutures can result in tight scleral flap thus reducing flow of aqueous into the bleb causing a low bleb and raised IOP.

If sutures are very loose, it will result in overfiltration leading to hypotony and flat anterior chamber in early post-operative

Financial or Other, Competing Interest: None.

Submission 30-03-2016, Peer Review 25-04-2016,

Acceptance 02-05-2016, Published 16-05-2016.

Corresponding Author:

Andleeb Ahangar,

Post Box Number 23,

General Post Office (GPO),

Srinagar-190001,

Jammu and Kashmir,

India.

E-mail: andleebali@gmail.com

DOI: $10.14260 /$ jemds/2016/553 period which causes choroidal detachment, suprachoroidal haemorrhage, cataract and bleb failure. This is where titration of filtration in early post-operative period becomes important. These complications can be overcome by laser suture lysis and releasable sutures; however, they have their own limitations. Conjunctival perforation, sudden hypotony, shallow anterior chamber and malignant glaucoma have been reported after laser suture lysis. $[2,3,4,5]$ and may not be possible in case of thick tenon and subconjunctival haemorrhage.

In case of releasable sutures, there is a potential to decrease the resistance to aqueous flow to a greater degree and hence result in overfiltration and sudden hypotony with flat anterior chamber and choroidal detachment. As sutures lie on the corneal surface and connects internally to the bleb and scleral flap, it provides a tract for infection resulting in blebitis. The exposed suture on the cornea may cause corneal abrasion and windshield wiper syndrome. Sutureless scleral tunnel trabeculectomy is a new modification of conventional trabeculectomy aimed to overcome many problems associated with conventional trabeculectomy.

\section{MATERIAL AND METHODS}

This study was conducted in the Department of Ophthalmology, Government Medical College, after approval was given by the Ethics Committee. In this study, 50 patients with diagnosis of primary open angle glaucoma were included. 
Informed consent was obtained from each patient before they underwent sutureless scleral tunnel trabeculectomy and were followed up for a period of six months post-operatively. Inclusion criteria were primary open angle glaucoma with intraocular pressure more than $21 \mathrm{mmHg}$ in spite of maximum tolerated medical therapy and/or advanced cupping and advanced visual field loss; intolerance to various side effects of glaucoma medication or poor compliance to medical treatment. However, cases of primary open angle glaucoma with presence of acute or chronic inflammatory disease, cataract, previous history of ocular surgery including failed trabeculectomy or previously done anterior segment laser therapy were excluded from the study. Cases of congenital glaucoma were also excluded. Pre-operative assessment included visual acuity using a Snellen chart, slit lamp examination, intraocular pressure measurement using Goldmann applanation tonometry, fundus examination (Cup disc ratio), gonioscopy and perimetry with Humphrey visual field analyser.

Surgery was conducted under local anaesthesia by peribulbar block. After cleaning the eyelids half of forehead and face with $10 \%$ povidone iodine, the eye was draped and a lid speculum was inserted. A traction suture using 4-0 silk was inserted at superior rectus. A fornix based conjunctival flap was made and bleeding episcleral vessels were cauterized. A linear partial thickness groove $5 \mathrm{~mm}$ long was made $2 \mathrm{~mm}$ behind the limbus and a scleral tunnel was created with a crescent knife which extended into the clear cornea $1 \mathrm{~mm}$ in front of the limbus. Anterior chamber paracentesis was performed at 10 o'clock or 2 o'clock position and viscoelastic substance was injected into the anterior chamber. Anterior chamber was then entered with a keratome knife. Trabeculectomy was performed using Kelly Descemet membrane punch and a peripheral iridectomy was performed using a pair of Vannas scissors. Viscoelastic substance was washed out and conjunctiva was sutured with 8-0 Vicryl. Subconjunctival injection of Dexamethasone and Gentamicin was given at 180 degrees away from the drainage site. Pad and bandage was applied for 24 hours. Intraoperative complications were recorded.

After removing the bandage, eye examination was done with particular attention paid to the condition of filtering bleb, cornea for striate keratopathy or oedema, anterior chamber depth and contents, pupil for reaction and shape. Topical antibiotic steroid drops were given for 6 weeks and topical cycloplegic eye drops for 1 to 2 weeks post-operatively.

Post-operative follow-up was done on 1 week, 1, 3 and 6 months. At each visit a full ocular examination was done including visual acuity, slit lamp examination, intraocular pressure measurement and fundus examination. Postoperative complications were recorded. Bleb type was also evaluated. On the basis of post-operative intraocular pressure, results of the surgical technique were labelled as absolute success (IOP $<21 \mathrm{mmHg}$ without antiglaucoma medication), qualified (IOP $<21 \mathrm{mmHg}$ with antiglaucoma medication) or failure (IOP $>21 \mathrm{mmHg}$ with antiglaucoma medication).

\section{RESULTS}

In our study, age in years ranged from 31 to 75 years. Mean age in years was $60.86 \pm 9.09$. Majority of our patients, i.e. $43(86 \%)$ patients were above 51 years; $2(4 \%)$ patients were in the age group of 31 to 40 years. There were $38(76 \%)$ males and 12
(24\%) females (Table 1). Right eye was operated in 23 (46\%) and left in 27 (54\%) patients (Table 2).

Pre-operatively, visual acuity was $6 / 18$ or better in 9 (18\%) cases and $6 / 24$ to $6 / 36$ in $19(38 \%)$ cases; $22(44 \%)$ cases had visual acuity $\leq 6 / 60$ (Table 3 ). Pre-operatively, 23 (46\%) cases had IOP in the range of $>21-30 \mathrm{mmHg}, 18$ (36\%) cases had IOP between 41-50 mmHg and only $1(2 \%)$ case had IOP $>50 \mathrm{mmHg}$ (Table 4). On fundus examination 12 (24\%) cases had a Cup Disc Ratio (CDR) of 0.5 to 0.6 , whereas 27 (54\%) cases had CDR of 0.7 to 0.8 (Table 5). Pre-operative visual field analysis showed mild field changes in $10(20 \%)$ cases, moderate field changes in $14(28 \%)$ cases and advanced field changes in 16 (32\%) cases. However, visual field analysis was not possible in $10(20 \%)$ cases, as they could not fixate due to poor visual acuity.

Mean post-operative IOP was $12.32 \pm 5.97 \mathrm{mmHg}$ in $1^{\text {st }}$ week and $16.00 \pm 2.31$ in $6^{\text {th }}$ month (Table 5). Statistically, there is highly significant reduction of IOP from preoperative level ( $p<0.001$ ). Average postoperative IOP fall at $6^{\text {th }}$ month from initial value was $14.50 \mathrm{mmHg}$ (Table 6). When postoperative status of vision at $6^{\text {th }}$ month was compared with preoperative vision, vision improved in $3(6 \%)$ cases by 2 lines on Snellen chart. Vision remained same in 43 (86\%) cases, whereas vision deteriorated in $4(8 \%)$ cases (Table 3). Out of these 4 cases 3 cases lost vision by 2 lines, whereas in 1 case vision deteriorated by 3 lines. In all 4 cases, deterioration of vision was secondary to development of cataract.

Post-operatively bleb was found in 45 (90\%) cases at 1 week, whereas it was absent in $5(10 \%)$ cases. The bleb score increased at subsequent follow-up visits and at 6 months 28 (56\%) cases had type $1 \mathrm{bleb}$ (thin pale polycystic). On the basis of IOP, 45 (90\%) cases showed absolute success and 5 (10\%) cases demonstrated qualified success. There was no failure.

There were no intraoperative complications. Most of the post-operative complications were seen in the immediate post-operative period. Shallow anterior chamber $(14 \%)$ was the most frequent post-operative complication that was treated with patching. Hyphema $(10 \%)$ was next most common complication; (8\%) cases showed hypotony with IOP $<6 \mathrm{mmHg}$, which showed improvement after 1 week. Postoperative inflammation was noticed in $2 \%$ cases that resolved following treatment with topical steroid eye drops. Cataract was seen post-operatively in $8 \%$ cases. Total number of complications exceeds total number of cases, because in some cases more than one complication developed (Table 7).

\begin{tabular}{|c|c|c|c|}
\hline $\begin{array}{c}\text { Age Group } \\
\text { (Years) }\end{array}$ & Male & Female & Total \\
\hline $31-40$ & $2(5.3 \%)$ & $0(0 \%)$ & $2(4.0 \%)$ \\
\hline $41-50$ & $3(7.9 \%)$ & $2(16.7 \%)$ & $5(10.0 \%)$ \\
\hline $51-60$ & $16(42.1 \%)$ & $3(25.0 \%)$ & $19(38.0 \%)$ \\
\hline $61-70$ & $15(39.5 \%)$ & $6(50.0 \%)$ & $21(42.0 \%)$ \\
\hline $71-80$ & $2(5.3 \%)$ & $1(8.3 \%)$ & $3(6.0 \%)$ \\
\hline Total & $38(100 \%)$ & $\mathbf{1 2}(100 \%)$ & $\mathbf{5 0 ( 1 0 0 \% )}$ \\
\hline \multicolumn{4}{|c|}{ Mean Age \pm SD $=60.86 \pm 9.09$} \\
\hline \multicolumn{4}{|c|}{ Table 1: Age and Sex Distribution } \\
\hline
\end{tabular}

\begin{tabular}{|c|c|}
\hline Laterality & Cases (\%) \\
\hline Right Eye & $23(46 \%)$ \\
\hline Left Eye & $27(54 \%)$ \\
\hline \multicolumn{2}{|c|}{ Table 2: Distribution of Cases } \\
According to the Eye Operated \\
\hline
\end{tabular}




\begin{tabular}{|c|c|c|c|c|}
\hline $\begin{array}{c}\text { Postoperative } \\
\text { Visual Acuity }\end{array}$ & $\begin{array}{c}\text { Preoperative } \\
\text { No. of Cases }\end{array}$ & Improved & Same & Deteriorated \\
\hline $6 / 6-6 / 9$ & 3 & 0 & 3 & 0 \\
\hline $6 / 12-6 / 18$ & 6 & 1 & 4 & 1 \\
\hline $6 / 24-6 / 36$ & 19 & 1 & 17 & 1 \\
\hline < or $=6 / 60$ & 22 & 1 & 19 & 2 \\
\hline
\end{tabular}

Table 3: Postoperative Visual Acuity at 6 Months in Relation to Preoperative Visual Acuity

\begin{tabular}{|c|c|}
\hline IOP (mmHg) & Cases (\%) \\
\hline$>21$ to 30 & $23(46.0 \%)$ \\
\hline 31 to 40 & $18(36.0 \%)$ \\
\hline 41 to 50 & $8(16.0 \%)$ \\
\hline 51 to 60 & $1(2.0 \%)$ \\
\hline Total & $50(100 \%)$ \\
\hline Mean IOP \pm SD $=\mathbf{3 0 . 5 6 \pm 7 . 1 6}$ \\
\hline $\begin{array}{c}\text { Table 4: Distribution of Cases According to } \\
\text { Preoperative Intraocular Pressure }\end{array}$ \\
\hline
\end{tabular}

\begin{tabular}{|c|c|c|c|c|}
\hline $\begin{array}{c}\text { IOP } \\
\text { (mmHg) }\end{array}$ & $\begin{array}{c}\mathbf{1} \text { st } \\
\text { Week }\end{array}$ & $\begin{array}{c}\mathbf{1} \\
\text { Month }\end{array}$ & $\begin{array}{c}\mathbf{3} \\
\text { Months }\end{array}$ & $\begin{array}{c}\mathbf{6} \\
\text { Months }\end{array}$ \\
\cline { 2 - 5 } & No. (\%) & No. (\%) & $\begin{array}{c}\text { No. } \\
(\%)\end{array}$ & $\begin{array}{c}\text { No. } \\
(\%)\end{array}$ \\
\hline$<5$ & 4 & 0 & 0 & 0 \\
& $(8 \%)$ & $(0 \%)$ & $(0 \%)$ & $(0 \%)$ \\
\hline \multirow{2}{*}{$6-20$} & 41 & 48 & 50 & 50 \\
& $(82 \%)$ & $(96 \%)$ & $(100 \%)$ & $(100 \%)$ \\
\hline$>21$ & 5 & 2 & 0 & 0 \\
& $(10 \%)$ & $(4 \%)$ & $(0 \%)$ & $(0 \%)$ \\
\hline Mean & $12.32 \pm$ & $13.56 \pm$ & $14.08 \pm$ & $16.00 \pm$ \\
$\pm S D$ & 5.97 & 3.64 & 2.45 & 2.31 \\
\hline \multicolumn{4}{|c|}{ Table 5: Distribution of Cases According to } \\
Postoperative Intraocular Pressure \\
\hline
\end{tabular}

\begin{tabular}{|c|c|c|c|}
\hline $\begin{array}{c}\text { Preoperative } \\
\text { IOP. } \\
\text { (Mean } \pm \text { SD) }\end{array}$ & $\begin{array}{c}\text { Last } \\
\text { Postoperative } \\
\text { IOP-6 months } \\
\text { (Mean } \pm \text { SD) }\end{array}$ & $\begin{array}{c}\text { Change } \\
\text { In } \\
\text { mmHg }\end{array}$ & $\begin{array}{c}\text { Significance } \\
\text { Level } \\
\text { (P - Value) }\end{array}$ \\
\hline $30.56 \pm 7.16$ & $16.00 \pm 2.321$ & 14.56 & $<0.001$ \\
\hline \multicolumn{2}{|c|}{ Table 6: Change in IOP from Pre-Operative Level } \\
\hline
\end{tabular}

\begin{tabular}{|c|c|}
\hline Complications & Cases (\% Age) \\
\hline Hyphema & $5(10 \%)$ \\
\hline Shallow Anterior Chamber & $7(14 \%)$ \\
\hline Hypotony & $4(8 \%)$ \\
\hline Uveitis & $1(2 \%)$ \\
\hline Raised IOP & $5(10 \%)$ \\
\hline Cataract Progression & $4(8 \%)$ \\
\hline Total No. of Cases & $14(28 \%)$ \\
\hline \multicolumn{2}{|c|}{ Table 7: Complications } \\
\hline
\end{tabular}

\section{DISCUSSION}

The surgical techniques used in conventional trabeculectomy have undergone several modifications and variations to maximize the benefits and at the same time decrease the complications associated with it. Conventional trabeculectomy involves dissection of a partial thickness scleral flap to cover the internal ostium and this flap is usually secured with sutures to regulate the flow of aqueous. However, the preparation of scleral flap and use of sutures may lead to many intra-operative and post-operative complications. Preparation of scleral flap is particularly very difficult in patients with sunken eyes and fragile scleral tissue. Excessive handling of the scleral flap may result in tearing of the flap and trauma to the scleral tissue. To control the aqueous flow, the scleral flap is sutured to the scleral bed. However, the scleral flap may get traumatized during suturing and there may be inadequate or excessive drainage of the aqueous if the sutures are too tight or too loose. Tight sutures leading to inadequate aqueous drainage and subsequently raised IOP may need to be removed or lysed postoperatively. However, suture removal or lysis may cause further complications like conjunctival hole with aqueous leak, sudden hypotony, shallow anterior chamber, malignant glaucoma and inflammation or may be unsuccessful due to thick overlying conjunctiva or blood over sutures.[2,3,4,5] Another technique which is being used to overcome the complications of conventional trabeculectomy is use of releasable sutures. This technique results is titrated outflow of the aqueous, thus preventing early postoperative hypotony and shallow anterior chamber. However, complications associated with this technique are windshield wiper keratopathy, corneal epithelial abrasion, subconjunctival bleed, failure to release the suture or the suture may form a tract for infection and cause blebitis and endophthalmitis.[6]

The sutureless scleral tunnel technique is a modification of the conventional trabeculectomy, which was used in our study to help solve the problems associated with the conventional technique. Creation of the scleral tunnel is simpler than dissection of the scleral flap and is helpful in eyes that have prior limbal wounds that tend to fall apart during free hand flap dissection. Very fragile flaps are less likely to tear with this technique. In this technique the punch produces a standard trabeculectomy aperture, the scleral tunnel acts like a valve that limits over-filtration during early postoperative period and there is more posterior diversion of aqueous which reduces the risk of post-operative leakage. Since in scleral tunnel trabeculectomy there is a single outflow edge in comparison to filtration through all three sides of scleral flap in conventional trabeculectomy, the flow per unit length is higher and therefore chances of fistula remaining patent are better in the scleral tunnel technique trabeculectomy. Since it is a sutureless technique, the amount of surgical manipulation and trauma are less. As no suture is applied to the scleral flap, there is minimal local tissue irritation and foreign body reaction leading to less fibrosis and scarring of conjunctival and scleral flaps. Sutureless technique may induce less postoperative astigmatism, as there is less postoperative steepening of the meridian of the incision site and there is no suture present to continuously alter the corneal curvature. Risk of suture associated complications like button holing of the conjunctival bleb or suture tract abscess, which might lead to endophthalmitis is removed.[7,8]

The present study was conducted on fifty eyes of patients attending Outpatient Department of Ophthalmology, Government Medical College. All the patients underwent trabeculectomy using sutureless scleral tunnel technique.

The mean age in our study was $60.86 \pm 9.09$ years. Majority (86\%) were above the age of 51 years. Lai JSM et al[7] reported in their study that mean age of patients who underwent trabeculectomy using sutureless scleral tunnel technique was $64 \pm 747.16$ years with $38.89 \%$ males and $61.11 \%$ females. Viori ML et al[8] in their study reported that mean age of patients who underwent scleral tunnel incision trabeculectomy was $68.7 \pm 11.4$ years. Most of the studies that have studied relationship of primary open angle glaucoma and age have confirmed that older the individual greater the prevalence of glaucoma. A male preponderance was observed 
in our study with 38 (76\%) patients being male and 12 (24\%) patients being female.

In the present study, average post-operative IOP fall of $14.50 \mathrm{mmHg}$ was observed at 6 months from a mean preoperative IOP of $30.56 \pm 7.16(\mathrm{p}<0.001)$, which is statistically significant. An absolute success rate at 6 months was $90 \%$. Our results were better than that reported by Lai JSM et al[7] and Yadollah Eslami et al[9] in their studies. Lai JSM et al[7] observed an absolute success rate of $79 \%$. They reported mean IOP of $26.6 \pm 3.6 \mathrm{mmHg}$ before surgery and $15.3 \pm 3 \mathrm{mmHg}$ postoperatively at 1 year following trabeculectomy using sutureless scleral tunnel technique in cases of primary open angle glaucoma. Yadollah Eslami et al ${ }^{[9]}$ in 2009 reported mean preoperative IOP of $29.29 \pm 8.22 \mathrm{mmHg}$, which fell to $15.00 \pm 3.862 \mathrm{mmHg}$ at 6 months post-operatively following scleral tunnel technique with an absolute rate of $65 \%$.

In the present study, visual acuity was maintained at the pre-operative level in the majority (86\%) of the cases. In $8 \%$ cases, visual acuity deteriorated and was secondary to development of cataract. Lai JSM et al[7] in their study reported that none of their patients had a decrease in visual acuity of more than two lines on the standard Snellen chart at one year follow-up except one in whom cataract developed.

The most common post-operative complication was shallow anterior chamber, which occurred in $14 \%$ cases. It is higher than that reported by Zaidi et al[10] (11.6\%) and Yadollah Eslami.[11] in 2008, but lower than that reported by Lai JSM et al[7] (15.8\%) and Yadollah Eslami et al[9] in 2009 (18\%). Shallow anterior chamber was treated successfully with patching. Post-operatively, hyphema was seen in $10 \%$ cases similar to that reported by Lai JSM et al[7] in their study. Post-operative hypotony was seen in $8 \%$ of cases as compared to $24.3 \%$ cases reported by Edmunds et al[12] and $22.7 \%$ cases reported by Yadollah Eslami et al[11] in 2008. In our study, post-operative cataract development was seen in $8 \%$ cases. It is lower than that reported by Zaidi et al[10] and Edmunds et al[12], but higher than that reported by Lai JSM et al.[7] Postoperative inflammation was seen in $2 \%$ cases that resolved within 2 weeks in response to topical steroid therapy. Zaidi et al[10] reported an incidence of $4.5 \%$ cases.

In our study, there was a statistically significant reduction of IOP from pre-operative level at the end of 6 months of follow-up and only $14 \%$ of cases had post-operative complication. Also most of the postoperative complications resolved following conservative management. Despite guarded outflow by sclerocorneal tunnel, over drainage may be a potential risk in the immediate post-operative period, which can however resolve by conservative measures. Hence, it can be concluded that trabeculectomy using sutureless scleral tunnel technique is a safe, effective, quick and easily mastered technique by which complications related to sutures can be overcome and this technique can be used on nearly all patients of primary open angle glaucoma being considered for conventional trabeculectomy.

\section{REFERENCES}

1. Raina UK, Tuli D, Mehta DK. Polyglactin sutures versus nylon sutures in scleral flap suturing in trabeculectomy. Ophthalmic Surg Lasers 1999;30(7):554-9.

2. Savage JA, Condon GP, Lytle RA, et al. Laser suture lysis after trabeculectomy. Ophthalmology 1988;95(12):1631-38.

3. Aykan U, Bilge AH, Akin T, et al. Laser suture lysis or releasable sutures after trabeculectomy. J Glaucoma 2007;16(2):240-5.

4. Wells AP, Bunce C, Khaw PT. Flap and suture manipulation after trabeculectomy with adjustable sutures: titration of flow and intraocular pressure in guarded filtration surgery. J Glaucoma 2004;13(5):4006.

5. Melamed S, Ashken azi I, Glovenski J, et al. Tight scleral flap trabeculectomy with postoperative laser suture lysis. Am J Ophthalmol 1990;109(3):303-9.

6. Thomas R, Jacob P, Braganza A, et al. Releasable suture technique for trabeculectomy. Indian Journal of Ophthalmology 1997;45(1):37-41.

7. Lai JSM, Lam DSC. Trabeculectomy using a sutureless scleral tunnel technique, a preliminary study. J Glaucoma 1999;8(3):188-92.

8. Vuori ML, Viitanen T. Scleral tunnel incisiontrabeculectomy with one releasable suture. Acta Ophthalmol Scand 2001;79(3):301-4.

9. Yadollah Eslami, Ghasen Fakhrai, Heyadr Amini, et al. The results of trabeculectomy using a sutureless scleral tunnel technique. International Ophthalmology 2009;29(5):329- 32.

10. Zaidi AA. Trabeculectomy a review and 4- year follow up. Br J Ophthalmol 1980;64(4):436-9.

11. Yadollah Eslami, Shahram Agharoka, Mohammed Taher Rajabi, et al. Sutureless versus conventional trabeculectomy for management of primary open angle glaucoma. Iranian Journal of Ophthalmology 2008;20(2):27-33.

12. Edmunds B, Thompson JR, Salmon JF, et al. The national survey of trabeculectomy iii. Early and late complications Eye 2002;16(3):297-303. 